\title{
Drogas y libre desarrollo de la personalidad, una nueva violencia, distorsionando lo que debe ser
}

\author{
Drugs and free personality \\ development, a new violence, \\ distorting what it should be
}

\author{
Agustín Antonio Herrera Fragoso*
}

https://doi.org/10.36105/mye.2020v31n2.04

\section{Resumen}

Nos encontramos frente a una distorsión de lo que se debe hacer, por lo que se quiere crear violencia bajo el tótem de la libertad y la autonomía, y que se va reflejando tanto a nivel interno (México) como internacional, bajo la justificación del libre desarrollo de la personalidad humana, situación que crea una distopia (antónimo de utopía, o lo que es lo mismo, una sociedad ficticia indeseable en sí misma) de la nueva libertad humana.

Palabras clave: violencia, libre desarrollo de la personalidad, libertad, drogas.

\footnotetext{
* Facultad de Bioética, Universidad Anáhuac México, México.

Correo electrónico: agusfrag80@hotmail.com

https://orcid.org/0000-0002-2401-6141

Recepción: 22 de noviembre de 2019. Aceptación: 12 de enero de 2020.
} 


\title{
I. Introducción
}

\author{
La finalidad del Estado es, por una parte, \\ posibilitar y realizar la vida buena en conjunto, \\ que no es establecida y definida por el propio Estado. \\ Por otra parte, preservar las condiciones de esa vida buena, \\ y preservar esas condiciones es lo que decide el propio Estado, \\ eso es el sentido de la soberanía.
}

(Aristóteles)

Hay cosas que nunca desaparecen. Entre ellas está la violencia; su forma de aparición varía según la constelación social. Actualmente, nos señala Byung Chul Han, ${ }^{1}$ muta de visible en invisible, de frontal en viral, de directa en mediada, de real en virtual, de física en psíquica, de negativa en positiva, y se retira a espacios subcutáneos, subcomunicativos, capilares y neuronales, de manera que pueda dar la impresión de que ha desaparecido.

Cuando se trata de coincidir con su contrafigura, la libertad se hace del todo invisible y la violencia material deja lugar a una violencia anónima, desubjetivada y sistématica, que se oculta como tal porque coincide con la propia sociedad.

La violencia macrofísica suele ser más sutil, como puede darse en el lenguaje, a través de la sobrecomunicación e información. Tanta información hace que la población se quede sin defensa inmunológica, sin capacidad de respuesta, dejando poca libertad, ya que la represión externa inhibe a la persona interna.

Actualmente, la violencia sufre una interiorización, se hace más psíquica y, con ello, se invisibiliza. Ya no sólo se despliega en una sujeción externa, sino interna; una coacción interna que se presenta bajo la sombra de la libertad. La autoinsumisión es más eficiente, porque va aparejada con sentimiento de libertad. Se desarrolla una autoagresividad, que en no pocas ocasiones se agudiza y acaba en la violencia del suicidio. 
Tenemos un mundo realmente invertido; lo verdadero es un momento de lo falso. El espectáculo es la afirmación de la apariencia y la afirmación de toda vida humana, o sea social, como apariencia. ${ }^{2}$ Muchos viven bajo motivaciones de un comportamiento hipnótico y teniendo a la autonomía y libertad como tótems, sin restricciones o contrapesos en responsabilidades sociales, rompiendo la armonía de la coexistencia relacional y de la convivencia familiar y social.

Dentro de esta disrupción, camina la autodestrucción que invade a la bioética y a su paso inmediato, a la biojurídica, en donde las leyes pierden su naturaleza de deber ser para beneficio y desarrollo humano. Así sucede ahora bajo los demiurgos jurisdiccionales de los tribunales constitucionales, situación que abordaré en y desde México.

\section{Antecedentes}

El Instituto Nacional sobre el Abuso de Drogas de los Estados Unidos de América señala que «cuando una persona se droga, puede ponerse violenta o enojarse. Puede hacerse daño a ella misma o hacerle daño a otro. El consumo de drogas puede hacer que las personas que están deprimidas se sientan peor; a veces hasta tan mal que pueden querer acabar con su vida. Una sobredosis de drogas puede matan». ${ }^{3}$

En una espiral histórica, nos encontramos nuevamente en una situación donde los condicionamientos repetitivos de las apetencias nublan la voluntad, a partir de lo cual se pierde la sindéresis (hacer el bien y evitar el mal) del derecho, y de toda evidencia científica y base ética y bioética de la salud humana, bajo el amparo de una resolución jurisdiccional.

Cuando la Corte expuso la primera sentencia que amparaba el uso lúdico de la marihuana, muchas personas se dieron el lujo de fumar en cualquier lugar público, perdiendo el sentido moral y de 
bien común, señalando que la Corte lo había permitido, y cuando se precisó que sólo era para quienes presentaron el amparo, se vinieron en cascada un sinfín de amparos para el mismo objetivo.

El efecto jurisprudencial se vio reflejado en los amparos en revisión 237/2014, 1115/2017, 623/2017, 547/2018 y 548/2018 del índice de la Primera Sala de la Suprema Corte de Justicia de la nación de México (ScjN), donde se controvirtió la regularidad de las normas que definen las actividades y usos legalmente permitidos en el país respecto de los estupefacientes. Lo objetivamente cierto y verdaderamente trascendente, en este caso, es que sus ejecutorias dan cuenta de que se analizó exclusivamente la constitucionalidad de algunos artículos de la Ley General de Salud, por cuanto hace a la prohibición implícita que tales normas prevén únicamente respecto del consumo personal de la marihuana, frente al derecho al libre desarrollo de la personalidad que tienen los gobernados, definiendo, a partir de las características específicas y propias del estupefaciente mencionado, que tal prohibición en particular no era una medida proporcional a los bienes legítimos que el Estado pretendía resguardar; a saber, la salud y el orden público.

En los fallos mencionados, el alto tribunal estableció expresamente que el tópico a resolver era si el consumo de la marihuana es o no capaz de afectar la salud y el orden público, a tal grado que su prohibición resulta ser la única medida idónea para salvaguardar tales valores.

\section{Análisis que realiza la SCJN}

A partir de esa premisa de la $1^{a}$ Sala de la SCJN, se analizaron diversos estudios y literatura científica relacionada con ese estupefaciente en específico, destacando, entre otros aspectos, los siguientes:

a) Que el consumo de marihuana en personas adultas no supone un riesgo importante para la salud y, sobre todo, es distinto de 
otras sustancias permitidas como el fumar tabaco e, incluso, menos dañina que el alcohol.

b) Que es una sustancia con una muy baja capacidad para generar dependencia entre sus usuarios.

c) Que tiene un nivel de incidencia muy bajo en el consumo de otras drogas más riesgosas, como la heroína o la cocaína.

d) Que la evidencia disponible permite afirmar que la marihuana por sí misma no induce la comisión de delitos violentos, pues su consumo tiende a inhibir los impulsos de agresión del usuario, ya que generalmente le produce estados de letargo, somnolencia y timidez.

A partir de lo cual se determinó que la prohibición del consumo personal de marihuana con fines lúdicos es inconstitucional, por el hecho de ser una medida desproporcional y, por ende, injustificada para salvaguardar la salud y el orden público, a partir de analizar sus características y efectos en lo particular.

Nos encontramos ante esta situación como una expansión de las libertades y de la voluntariedad, a partir de la cual esa nueva libertad se trueca en nuevas coerciones, sin conciencia de las daños reales y evidenciados desde la ciencia actual (más adelante se especificarán) y de los efectos que dañan la salud humana.

A partir de las anteriores resoluciones se amplió el tema hasta el consumo de cocaína. En efecto, el 20 de agosto de 2019 un juez federal de la Ciudad de México concedió dos amparos que ordenan a la Comisión Federal para la Protección contra Riesgos Sanitarios (COFEPRIS) autorizar la posesión, transporte, empleo y uso de la cocaína. ${ }^{4}$ Posteriormente, en un amparo en revisión, el tribunal colegiado señaló: «lo objetivamente cierto es que resulta un hecho notorio el que se trata de sustancias considerablemente distintas, pues: a) la cocaína, a diferencia de la marihuana, es una droga producto de un proceso químico previo, aspecto que la propia norma citada evidencia al enunciarla junto con su nombre químico (éster metílico de benzoilecgonina); b) es base para fabricar otros narcó- 
ticos; c) a diferencia de la marihuana, su capacidad de generar dependencia es considerablemente mayor, entre otros aspectos; incluso, el propio alto tribunal calificó a la cocaína como una droga muy riesgosa, aunque no abundó más sobre el tema ni en las razones que sustentaron su aseveración».

Tras declararse incompetentes para conocer la inconstitucionalidad del asunto, el tribunal colegiado remitió a la SCJN para que conociera del mismo, señalando:

«De ahí que lo resuelto en tales asuntos y, por consecuencia, los criterios jurisprudenciales que generaron, a saber, las jurisprudencias 1a./J. 3/2019, 1a./J. 9/2019, 1a./J. 10/2019 y 1a./J. 25/2019 de rubros: Derecho al libre desarrollo de la personalidad. La probibición para el autoconsumo de maribuana contenida en la Ley General de Salud incide prima facie en el contenido de dicho derecho fundamental. Probibición absoluta del consumo lúdico de maribuana. No es una medida proporcional para proteger la salud y el orden público. Inconstitucionalidad de la probibición absoluta al consumo lúdico o recreativo de maribuana prevista por la Ley General de Salud, y probibición absoluta del consumo lúdico de la maribuana. No es una medida necesaria para proteger la salud y el orden público, respectivamente, no sólo no sean aptos para resolver la regularidad de los preceptos combatidos, por cuanto hace a una presunta prohibición implícita del consumo personal y lúdico de la cocaína, pues se trata de un estupefaciente diverso, cuyas características y efectos, además, no son nada parecidos a la marihuana, incluso por cuanto hace a su importancia y rendimiento económico para el narcotráfico, aspectos y diferencias que se consideran de particular trascendencia para resolver sobre el tema específico sujeto a debate y, por ende, refuerzan la necesidad de que sea la SCJN la que se avoque a analizar el tema debatido, en razón de su particular y notoria importancia tanto para el sistema jurídico como y, sobre todo, para la sociedad, derivado de la gran problemática que significa el consumo de drogas, así como lo controversial que para la colectividad significa dicho tópico». 
Drogas y libre desarrollo de la personalidad, una nueva violencia

\section{La pendiente resbaladiza del libre desarrollo de la personalidad, expuesta por la SCJN}

Ahora bien, el libre desarrollo de la personalidad, tan encumbrado en nuestro tiempo, se revela como un proyectil, que termina contra sí mismo. Al respecto cabe referir, para efectos argumentativos, la tesis más paradigmática en el tema:

Derecho al libre desarrollo de la personalidad. La probibición para el autoconsumo de maribuana contenida en la ley general de salud incide prima facie en el contenido de dicho derecho fundamental. ${ }^{5}$ Esta Primera Sala entiende que el derecho fundamental al libre desarrollo de la personalidad permite, prima facie, que las personas mayores de edad decidan sin interferencia alguna qué tipo de actividades recreativas o lúdicas desean realizar, así como llevar a cabo todas las acciones o actividades necesarias para poder materializar esa elección. De esta manera, la elección de alguna actividad recreativa o lúdica es una decisión que pertenece indudablemente a la esfera de autonomía personal que debe estar protegida por la Constitución. Esa elección puede incluir la ingesta o el consumo de sustancias que produzcan experiencias que en algún sentido «afecten» los pensamientos, las emociones y/o las sensaciones de la persona. En esta línea, se ha señalado que la decisión de fumar marihuana puede tener distintas finalidades, entre las que se incluyen «el alivio de la tensión, la intensificación de las percepciones o el deseo de nuevas experiencias personales y espirituales». Estas experiencias se encuentran entre las más personales e íntimas que alguien pueda experimentar, de tal manera que la decisión de un individuo mayor de edad de «afectar» su personalidad de esta manera con fines recreativos o lúdicos se encuentra tutelada prima facie por el derecho al libre desarrollo de ésta.

Situación que la Corte, como demiurgo jurídico, establece como una ampliación de libertades para que todas las personas mayores de «18 años de edad» tiendan a su libre desarrollo de la personalidad, bajo sus apetitos sensibles (deseos e impulsos) y no por apetito racional (la voluntad inteligente). 
Por otro lado, y retomando lo señalado al inicio, la rivalidad mimética de querer poseer lo que los demás desean, también es la fuente de la nueva violencia. Y mientras se incita a legalizar diversas drogas (opio y marihuana), justificado para controlar los mercados de la droga en México ${ }^{6}$ y reducir la violencia existente, el fomento de la adicción avanza más invulnerable, perdiendo más y más la otredad y extrañeza del mundo social.

En ese sentido, al Estado, como Leviatán, sólo le interesa resolver lo inmediato, por un lado, consintiendo a grupos y personas que impulsen sus agendas e intereses; exigiendo a través de pseudo derechos y libertades el justificar sus apetencias, legitimadas por transformaciones legislativas, perdiendo el rumbo para salvaguardar la salud, integridad personal y crecimiento humano de sus conciudadanos, bajo una moralidad líquida, que se esparce en todas direcciones y que afecta a todos los operadores deontológicos (juristas, legisladores, médicos, bioeticistas, profesionales de la salud, etc.), y alienando su conciencia bajo efectos dañinos.

Por otro lado, las instituciones u órganos gubernamentales se enaltecen de forma exuberante, creyendo resolver situaciones complejas de forma inmediata y eficaz, para seguir teniendo el control de los ciudadanos, manteniendo sus privilegios y canonjías derivados del abuso de sus cargos públicos, dejando de lado su estructura de conciencia, afectando a todas las personas y, en particular, a las generaciones futuras, $y$, en el ámbito jurisdiccional, se ve invadido por la «verifobia» jurídica, donde se da privilegio a lo que impulsan los grupos de presión a través de las redes sociales e intereses individuales, posicionando lo conveniente, cuando lo que tiene que impulsar es la verdad y que prime la justicia.

\section{Análisis del caso}

Es de destacar que no es lo mismo apelar a la violencia autogenerada en nombre de la autonomía y libertad, donde el culpable es el 
individuo impulsor, que luchar por el bien común, que, por lo regular, es tardado y conlleva esfuerzos de largo plazo, no visibles para su necesidad de votantes de forma inmediata, como se realizó en Islandia. Ahí, a través de reformas legislativas más estrictas (desde 2002 la prohibición de que toda persona menor de 16 años pueda estar sola en la calle después de las diez de la noche, salvo casos excepcionales) y políticas públicas (Youth in Iceland, 1998) abocadas a los jóvenes (actividades extraescolares, como deportes, música, teatro y danza) después de veinte años, se redujo el consumo de alcohol entre los jóvenes del $42 \%$ al $5 \%$, y el del cannabis, del 17\% al 7\%, cambiando de un círculo vicioso a uno virtuoso, en corresponsabilidad con los padres, su familia, la sociedad, la iniciativa privada y el gobierno. El objetivo es procesar las causas, fortalecer la protección y reducir los factores de riesgo.

En el Informe Mundial de Drogas 2019, Antonino De Leo, representante de la Oficina de Naciones Unidas contra la Droga y el Delito (ONUDD, o UNODOC, del inglés United Nations Office on Drugs and Crime), dijo que cerca de 271 millones de personas en el mundo usaron drogas en el último año, lo que representa 5.5\% de la población de 15 a 64 años, y 31 millones presentaron algún trastorno relacionado con el uso de sustancias, cifra que equivale al $11 \%$ de los usuarios de drogas. Asimismo, 34.2 millones de personas de 15 a 64 años usaron estimulantes de tipo anfetamínico; 18.2 millones en el mismo rango de edad usaron cocaína, y 34.3 millones usaron opioides. ${ }^{7}$

Datos aproximados al respecto indican que más de 16 millones de personas en México (23.5\%) son fumadores, y 17.4\% son exfumadores. En cuanto al problema de consumir bebidas con alcohol, se sabe que poco más de 22.7 millones reportan como bebida preferida a la cerveza; 14.7 a los destilados; 7.3 a los vinos de mesa; 3.8 a las bebidas preparadas tipo «coolers», y una proporción menor (2.4 millones) ingiere aguardientes, pulque o alcohol de $96^{\circ}$, que son más comunes en poblaciones rurales. 
En México, de acuerdo con el análisis del Consejo Nacional contra las Adicciones (CONADIC), poco más de 3.5 millones de individuos de 12 a 65 años de edad de todo el país han probado alguna droga ilegal, como marihuana o cocaína, aunque en este rubro también se encuentran sustancias inhalables y aquellas que tienen una utilidad médica y se consumen sin prescripción. La relación es abrumadoramente favorable para los hombres: 3.3 por cada mujer; es decir, 2,697,970 hombres frente a 810,671 mujeres. ${ }^{8}$

En el rango de la población mexicana de 12 a 65 años, la Encuesta Nacional de Adicciones (ENA) indica que entre 2008 y 2011 aumentó de 3.9 a 5.7 millones el número de personas que consumieron enervantes ilegales como marihuana, inhalables, cocaína, heroína, estimulantes anfetamínicos y otras (sin considerar las de uso médico). Es decir, que, contrario al objetivo de la Asamblea General de Naciones Unidas de alcanzar una sociedad internacional libre del abuso de enervantes, el uso de sustancias ilícitas en el país se incrementó en dos puntos porcentuales: del 5.2\% al 7.2\% en el transcurso de tres años.

Asimismo, el número de personas dependientes de enervantes en México pasó de 450 mil en 2008, a 550 mil en 2011.

La edad de mayor riesgo de consumo de estupefacientes, tanto legales como ilegales, se ubicó, además, entre los 10 y los 18 años, que es la población objetivo de atención de los Centros de Integración Juvenil (CIJ); en tanto que la edad de inicio de consumo de cualquier tipo de enervante oscila hoy entre los diez y los 14 años.

Durante 2012, los CIJ recibieron de hecho a 24,728 usuarios de enervantes ilegales, de los que 42\% tenía menos de 18 años.

Ante este panorama, Nora Volkow comparte que el más reciente estudio en Estados Unidos de Norteamérica (2015) reporta una disminución en el consumo de cocaína, metanfetamina, tabaco y alcohol, pero «vemos un aumento en las drogas de prescripción, que es actualmente una de las problemáticas más severas, y en la marihuana». 
Por su parte, la Asamblea de la Organización Mundial de la Salud, en su Resolución A70/29 de fecha 27 de marzo de 2017, señala que «se pueden atribuir al consumo de drogas psicoactivas más de 450,000 muertes al año. La carga de morbilidad atribuible a las drogas corresponde al 1,5\% del total de la carga de morbilidad, y se calcula que el uso de drogas inyectables es responsable de un $30 \%$ de las nuevas infecciones por el VIH fuera del África subsahariana, y contribuye significativamente a las epidemias de hepatitis B y hepatitis $\mathrm{C}$ en todas las regiones». ${ }^{10}$

Es sabido que existen drogas de origen natural, como la cocaína, los opiáceos y el cannabis, y drogas de origen sintético, como los estimulantes de tipo anfetamínico, tradicionales y las llamadas NSP (Nuevas Sustancias Psicoactivas), que en el Glosario del Informe Mundial sobre las Drogas 2017, ${ }^{11}$ son definidas como «sustancias objeto de uso indebido, ya sea en su estado puro o en preparados, que no están sujetas a fiscalización con arreglo a la Convención Única de 1961 sobre Estupefacientes ni al Convenio de 1971, pero que pueden entrañar un peligro para la salud pública. En este contexto, el término «nuevas» no se refiere forzosamente a nuevas invenciones, sino a sustancias que han empezado a circular recientemente». A este grupo pertenecen, por ejemplo, los cannabinoides sintéticos, siendo el más conocido el Spice o K2. ${ }^{12}$

El uso de drogas para fines medicinales ha sido regulado, tanto a nivel nacional como internacional, estableciéndose un catálogo de sustancias lícitas e ilícitas, así como un estricto control en su producción, distribución, importación y consumo, ya sea para la cura o el manejo de distintas enfermedades o para paliar el dolor. Actualmente, se está realizando una reforma mayor derivada de la realizada para uso medicinal y derivado de las resoluciones citadas de las SCJN, para incluir el uso personal o lúdico.

Actualmente, en el Informe Mundial sobre las Drogas 2019 se hace un llamado a aumentar los recursos para ampliar la prevención y el tratamiento del consumo de drogas, citando al Secretario General de las Naciones Unidas, António Guterres, el Sr. De Leo 
apuntó que: «...la prevención y el abordaje de los retos relacionados con las drogas en toda su complejidad es esencial para cumplir una promesa mundial fundamental, consagrada en los Objetivos de Desarrollo Sostenible: no dejar a nadie atrás». ${ }^{13}$

Destacó las seis conclusiones y consecuencias en materia de políticas que recomienda el Informe: 1. Ayudar a quienes lo necesitan; 2. Mitigar las concentraciones de alto riesgo; 3 . La paradoja mundial por exceso y por defecto; 4 . El cumplimiento de la ley es una parte esencial de la solución; 5. Es necesario vigilar de cerca los mercados del cannabis, y 6. La cambiante complejidad pone de relieve la necesidad de seguir investigando. De lo cual se deriva que el pronunciamiento es de prudencia, análisis y actuación por el bien común de todos.

Por otro lado, una sociedad regida por la histeria de la supervivencia es una sociedad de zombies, que no son capaces de vivir hacia un futuro cierto; se venden con cantos de sirena, sobre propuestas de corto plazo, sin pensar en los daños colaterales o efectos negativos en el largo plazo, bajo un esquema ajeno a la cultura, valores y realidad del país, por creer que es un paliativo para disminuir la delincuencia organizada en el narcotráfico con la marihuana.

Cabe destacar que parte de la argumentación del libre desarrollo de la personalidad tiene un antecedente en relación con el consumo lúdico de la marihuana y sus actividades conexas, donde, la Primera Sala (ver página 41 de la primera resolución) cita un voto disidente de 1972 del juez Levinson, en la sentencia de la Corte Suprema de Hawaii en el caso Hawaii State v. Kantner, del siguiente modo:

«La elección de alguna actividad recreativa o lúdica es una decisión que pertenece indudablemente a la esfera de autonomía personal que debe estar protegida por la Constitución. Esa elección puede incluir, como ocurre en el presente caso, la ingesta o el consumo de sustancias que produzcan experiencias que en algún sentido "afecten" los pensamientos, las emociones y/o las sensaciones de la persona [cita del voto]. En esta línea, se ha señalado que la 
decisión de fumar marihuana puede tener distintas finalidades, entre las que se incluyen "el alivio de la tensión, la intensificación de las percepciones o el deseo de nuevas experiencias personales y espirituales" [cita del voto]. Así, al tratarse de "experiencias mentales", éstas se encuentran entre las más personales e íntimas que alguien pueda experimentar, de tal manera que la decisión de un individuo mayor de edad de "afectar" su personalidad de esta manera con fines recreativos o lúdicos se encuentra tutelada prima facie por el derecho al libre desarrollo de ésta [cita del voto]».

Por otro lado, también existe el antecedente de Colombia en referencia al consumo de drogas. Este derecho sirvió como fundamento para el permiso de la dosis personal, así como para su despenalización. Determina la Corte que dicho consumo es parte de la autodeterminación individual.

«En otros términos: el legislador puede prescribirme la forma en que debo comportarme con otros, pero no la forma en que debo comportarme conmigo mismo, en la medida en que mi conducta no interfiere con la órbita de acción de nadie (...). Si el derecho al libre desarrollo de la personalidad tiene algún sentido dentro de nuestro sistema, es preciso concluir que, por las razones anotadas, las normas que hacen del consumo de droga un delito, son claramente inconstitucionales». ${ }^{14}$

Así, la Primera Sala de la SCJN construyó la relación del consumo lúdico de la marihuana con el derecho al libre desarrollo de la personalidad e hizo suyo el voto disidente del juez Levinson en la tesis aislada de jurisprudencia 1a. CCLX/2016 (10a.) de rubro: Derecho al libre desarrollo de la personalidad. La probibición para el autoconsumo de maribuana contenida en la Ley General de Salud incide prima facie en el contenido de dicho derecho fundamental, citada previamente.

Esta construcción dio pie al examen de proporcionalidad de los preceptos impugnados, en el que se determinó que la medida sí tiene una finalidad constitucionalmente válida, y era una medida idónea que buscaba proteger la salud y el orden público, pero las porciones normativas no superaron el test de proporcionalidad, en el 
grado de necesidad y proporcionalidad en sentido estricto, para prohibir administrativamente el ejercicio de este «derecho». De dicha sentencia, posteriormente se emitieron ocho tesis aisladas de Jurisprudencia, con su debida gradualidad, y cada resolución tiene sus debidas particularidades.

Ahora bien, el fundar el libre desarrollo de la personalidad para el uso lúdico del consumo de la marihuana y conforme a los 18 años de edad, por ser la mayoría de edad en México, enfatizando que toda persona tiene todas sus capacidades en plenitud y poder realizar lo que se le antoje y apetezca, aun en contra de su salud e integridad personal, es vivir bajo un esquema decimonónico, por establecer esa edad de forma descontextualizada con la actualidad y bajo la evidencia científica.

A partir de lo cual y, bajo el esquema de lo que aborda la Corte Interamericana de Derechos Humanos (Corte IDH) y bajo el principio de interpretación evolutiva, afirma: «que los tratados de derechos humanos son instrumentos vivos, cuya interpretación tiene que acompañar la evolución de los tiempos y las condiciones de vida actuales». ${ }^{15}$ Sobre el caso que nos ocupa, se deberá allegar la información científica que devela de forma objetiva el status quo del bien común, mismo que debe ampliar el espectro de protección y hermenéutico, actualizándose el principio pro persona (en sentido estricto), el cual ha sido identificado de forma genérica con la protección eficaz de la persona. ${ }^{16}$

A mayor abundamiento, la Convención Americana de Derechos Humanos, así como los demás tratados de derechos humanos, se inspiran en valores comunes superiores (centrados en la protección del ser humano), no así en simples pretensiones.

Los estudios científicos actuales han demostrado que el cerebro de los adolescentes, en especial la corteza prefrontal, termina de desarrollarse hasta los 21-25 años de edad. ${ }^{17}$ Las investigaciones indican que los cerebros en desarrollo son mucho más susceptibles a los efectos negativos de la marihuana y de otras drogas, ${ }^{18}$ como la 
impulsividad, pobre control de las emociones, mala toma de decisiones, exposición a conductas de riesgo y desempleo.

Llevado a cabo un estudio a lo largo de trece años, se demostró la relación entre el consumo recreativo de la marihuana a temprana edad y hasta personas menores de 25 años y el aumento significativo de problemas de salud para personas mayores de 25 e incluso en años posteriores, como son: problemas respiratorios, malestar general, problemas neurocognitivos y un menor rendimiento y aprovechamiento académico. ${ }^{19}$ Evidencia así que la etapa de desarrollo neurológico culmina entre los 25 y 26 años en promedio.

Por ello, los adolescentes con dependencia muestran déficit de memoria en el corto plazo, aun después de seis semanas de abstinencia. El consumo de altas cantidades se asocia con la presencia de dificultades para la atención, actividad motriz lenta y alteraciones severas de la memoria. Otros estudios han demostrado que dichos efectos en los fumadores crónicos perduran más allá del periodo de intoxicación y empeoran con el tiempo al mantener un consumo regular. Esto favorece un mal desempeño académico con la subsecuente deserción escolar, desempleo, dependencia económica de familiares, malas relaciones interpersonales e insatisfacción individual.

Se estima que uno de cada nueve usuarios de marihuana se volverá dependiente. En aquellos que inician el consumo en la adolescencia, el riesgo de dependencia aumenta, presentándose en uno de cada seis consumidores. ${ }^{20}$

La literatura médica no sólo sugiere desventajas neurocognitivas en el empleo de la marihuana en los dominios de atención y memoria que persisten más allá de la abstinencia, sino que sugiere posibles alteraciones macroestructurales en el cerebro (cambios morfométricos en la sustancia gris); cambios en la integridad de los tractos de sustancia blanca (pobre coherencia en fibras de sustancia blanca), y anormalidades en el funcionamiento neuronal. Cuanto más temprano sea el inicio de uso, peor será su pronóstico. ${ }^{21}$ 
Por lo que, si se quiere permitir el consumo de la marihuana de forma coherente frente a la evidencia científica, basado en el libre desarrollo de la personalidad, primero se deberá aumentar la mayoría de edad e implementar políticas públicas como las de Islandia, y después de cosechar el efecto virtuoso que realicen las reformas que se estimen pertinentes, fomentar la cohesión familiar y la responsabilidad personal y social.

Por otro lado, y en virtud de las responsabilidades y conocimiento que se tiene de los efectos de consumo lúdico de la marihuana o de cualquier otra droga, bajo la responsabilidad y orden social, que sean los consumidores, con conocimiento de causa, quienes paguen las consecuencias de sus efectos en la atención de su salud y en los costos de sus seguros.

Atendiendo la interdependencia de los derechos humanos y su debida protección, el Estado debe implementar, más bien, políticas, programas y planes que sean necesarios para que, respetando la libre determinación de las personas y el derecho a la salud, se fomente la información basada en la evidencia científica sobre los riesgos del consumo del cannabis psicoactivo en los adultos jóvenes, especialmente en aquellos mayores de 18 años y menores de 25, con el objeto de inhibir su consumo.

Retomando a Aristóteles: «Todo arte y toda investigación e, igualmente, toda acción y libre elección, parecen tender a algún bien; por esto se ha manifestado con razón que el bien es aquello hacia lo que todas las cosas tienden»». ${ }^{22}$ En esta tesitura, se deberá enderezar el rumbo, con políticas y normatividad jurídica adecuada, proporcional y armónica con el bien común y el desarrollo saludable de todas las personas, bajo el amparo de un Estado que se preocupe por todos sus gobernados y, en particular, por la niñez y las generaciones futuras.

Enfatizando sobre el libre desarrollo de la personalidad y siguiendo la definición de Emmanuel Kant, la libertad no significa la validez de cualquier decisión, sino solamente la de aquellas accio- 
nes o decisiones racionales y responsables. Este último término se refiere en especial a decisiones que no causen daño a terceros. ${ }^{23}$

En referencia al derecho al libre desarrollo de la personalidad como derecho general de la personalidad, del cual surgen y se subsumen los derechos fundamentales implícitos, el Tribunal Constitucional Alemán ha mencionado reiteradamente:

«Al derecho fundamental se le atribuye la función de proteger los elementos de la personalidad, que no son objeto de las especiales garantías de la libertad consagradas en la ley Fundamental, pero que tienen igual importancia para el desarrollo y constitución de la personalidad del individuo (cf. bVerfGE 54, 148 [153]; 99, 185 [193]). La necesidad de una protección plena deriva principalmente de nuevas amenazas que pongan en peligro el desarrollo de la personalidad y que surgen -la mayoría de las veces- a la par del avance técnico-científico (cf. BVerfGE 54, 148 [153]; 65,1 [41]). La subordinación de una solicitud concreta de protección jurídica a los diversos aspectos del derecho de la personalidad debe hacerse en vistas de los peligros que amenazan la personalidad y tomando en cuenta las circunstancias concretas del caso que motiva el conflicto». ${ }^{24}$

Sobre el alcance y límites de este derecho, en un caso referente al consumo de estupefacientes, el Tribunal dispuso que el consumo de drogas no puede ser amparado bajo el derecho al libre desarrollo de la personalidad, en cuanto que, dentro de las limitaciones de éste, se encuentra el interés público, y dicha práctica resulta perniciosa a la salud pública, por lo cual el Tribunal concluye que no existe un derecho a intoxicarse, por los siguientes motivos:

«El Art. 2, párrafo 1 de la ley Fundamental protege toda forma de actuación humana, sea cual fuere lo que conlleve la respectiva actividad para el desarrollo de la personalidad (cf. bVerfGE 80,137 [152]). La protección absoluta y, por tanto, la actividad del poder público se encuentra restringida sólo a la esfera de la configuración de la vida privada (cf. bVerfGE 6, 32 [41]; 54,143 [146]; 80,137 [153]). De ahí que no se pueda contar dentro de ésta el comercio 
de drogas, y, de manera especial, el consumo personal, atendiendo sus múltiples efectos e interacciones sociales. Por lo demás, la libertad general de actuación se encuentra garantizada -salvedad hecha de las restricciones contempladas en la segunda mitad de la segunda frase del párrafo $1^{\circ}$ del Art. 2 de la ley Fundamental que la obligan, por consiguiente, a respetar el orden constitucional- (cf. bVerfGE 80, 137 [153]) (...) Tales injerencias en la libertad personal sólo son admisibles, en general, en el evento en que así lo requiera la protección de terceros o el interés común, atendiendo al principio de proporcionalidad, sin perjuicio de que tales intervenciones puedan ser consideradas también (bajo determinados presupuestos), a fin de evitar que la persona en cuestión se inflija a sí misma un grave perjuicio personal (cf. bVerfGE 22, 180 [219]; 58, 208 [224 y ss.]; 59, 275 [278]; 60, 123 [132])». ${ }^{25}$

En esa inteligencia, «todo actuar humano debe tener límites para no afectar al otro, límites que como última ratio establece el derecho, pero como valores fundamentales en la convivencia social vienen señalados por la ética y se materializan en los derechos humanos». ${ }^{26}$ Así se salvaguarda también a la persona y su integridad personal.

El actuar en libertad es tomar en cuenta las consecuencias, y aceptar la responsabilidad de las mismas. Este actuar deberá ser discernido previamente y no después. En esta guisa, es responsabilidad tanto del Estado como de la misma humanidad marcar límites y no afectar a terceros.

Si se profundiza el sentido del libre desarrollo de la personalidad establecido previamente por la primera sala de la SCJN, se actualizan dos variantes en el relativismo moral, y son:

1. Todo hombre debe seguir la moral dominante en la sociedad en que vive, $\mathrm{y}$

2. Cada uno debe seguir su propio capricho y hacer lo que le venga en gana.

Y, como Pilatos, se lavan las manos, justificando la pretensión de quienes se ampararon y no el principio pro persona (beneficia más a la persona humana), tal y como lo argumentó el tribual alemán. 
Lo que está en juego es la persona humana y el logro de su verdadera plenitud o desarrollo. Porque tal como ha advertido Robert Spaemann, «El abandono del concepto de teleología natural vino impuesto, como se dijo, por un interés fundamental, el interés en el sometimiento de la naturaleza. Para quien quiera hacer con una cosa todo lo que se le antoje, la pregunta de a qué aspira de suyo esta cosa ha de resultar inoportuna». ${ }^{27}$

\title{
VI. Conclusiones propositivas
}

\author{
El mal no es ningún concepto; \\ es más bien un nombre para lo amenazador; \\ algo que sale al paso de la conciencia libre \\ y que ella pueda realizar. \\ (Rüdiger Safranski)
}

De lo que estamos advirtiendo en nuestro país, se concluye que el concepto de libertad se traduce como pura espontaneidad o autonomía absoluta. Se trata de una libertad sin naturaleza; antes bien, contrapuesta a la naturaleza. Una autonomía sin límites, que deja al sujeto en capacidad efectiva de seguir las propias apetencias y secundar las preferencias personales sin ningún tipo de restricción.

Es lo que se conoce en el ámbito de la filosofía política contemporánea como «libertad negativa», según la expresión definitivamente consagrada por Isaiah Berlin, para quien «libertad» en este sentido significa «estar libre de interferencias más allá de una frontera variable, pero siempre reconocible». ${ }^{28}$ Básicamente, lo que Berlin entiende por libertad negativa no es más que la libertad psicológica o libre albedrío...» ${ }^{29}$

Ahora bien, el hacer lo que uno quiera, con tal de que no perjudique a otro; que el Estado no deba interferir en la libertad individual para proteger a una persona de sí misma, o para imponerle lo que la mayoría crea que es la mejor manera de vivir; que una perso- 
na deba rendir cuentas a la sociedad sólo cuando afecte a otros, y no cuando su independencia de derecho no afecte a nadie más; que su independencia es un derecho absoluto, sobre sí mismo, sobre su cuerpo y su mente, ya que el individuo es soberano..., ${ }^{30}$ toda esta forma de pensar es una estructura utilitarista establecida por J. Stuart Mill. En este contexto, un Estado democrático de derecho bajo un soporte de derechos humanos deberá obrar con una prudencia adecuada para todas las personas, y no sólo enfocarse a la promoción del placer y a la prevención del dolor ${ }^{31}$ sin asumir el resto de consecuencias.

En este sentido se propone no legislar sobre leyes que protegen a las personas del daño que puedan hacerse a sí mismas, mientras no haya terceros que salgan perjudicados, y mucho menos legislar sobre la moral. ${ }^{32}$

Sobre este particular análisis del Estado libertario, Robert Nozick señala: «hay que preguntarse qué debe hacer el Estado, si es que debe hacer algo. Llega a la conclusión de que sólo se justifica un Estado mínimo, que se limite a hacer cumplir los contratos y a proteger a las personas de la fuerza, el robo y el fraude. Cualquier Estado que vaya más allá violará el derecho de las personas a que no se les fuerce a hacer ciertas cosas, y no estará justificado». ${ }^{33}$

De aquí podría decirse, como lo señaló Legaz Lacambra, que el Derecho «es un punto de vista sobre la justicia sólo y en cuanto constituye un orden de la vida social y una seguridad de las condiciones mínimas que la hacen posible», condiciones que deben ser racionales en busca siempre del bienestar de todas y cada una de las personas, siendo garante el Estado de los derechos fundamentales, como es la vida, la integridad personal y su salud.

De lo anterior se puede colegir que el telos humano constituye un referente metafísico-axiológico, desde el cual es posible juzgar qué opciones vitales contribuyen a desarrollar la personalidad y qué opciones la obstaculizan y socavan.

En virtud de su naturaleza espiritual o racional, la persona es apertura, ${ }^{34}$ la cual conduce a una corriente de interacción entre el 
yo personal y la realidad, de manera particular con el tú personal de los demás seres humanos. Tal interacción se traducirá, en muchos casos, en un incremento de su ser. ${ }^{35}$

El solo querer satisfacer placeres por querer quedar bien con determinadas pretensiones, en detrimento de su salud e integridad personal, justificando que así será feliz y que nadie podrá impedírselo, es como se burla Sócrates en Gorgias: el hombre más feliz tendría que ser el que siempre tiene sarna y siempre puede rascarse.

Como última reflexión y como lo estableció el Grupo Latinoamericano de Estudios sobre Derecho Penal Internacional en relación con el problema de las drogas: «4. El recurso al derecho penal como instrumento para enfrentar el problema de las drogas debe guiarse por los principios de necesidad y última ratio. El derecho penal no puede ser el instrumento prevalente de los Estados. Tal problema debe ser abordado de manera interdisciplinaria e integralı. ${ }^{36}$

Por lo cual, criminalizar determinados actos empeora las circunstancias y daña más el tejido social. Hay que buscar, además, una solución para las personas recluidas por la portación ilegal de marihuana, con base en un programa de justicia restaurativa y su variante terapéutica, propuesta que hay que analizar con detenimiento y sin afectar a terceros. Por otro lado, la bioética, en su plano transdisciplinar, puede brindar las herramientas necesarias y proporcionales para la mejor toma de decisiones en el plano biojurídico, en aras de la coexistencia relacional.

\section{Notas bibliográficas}

${ }^{1}$ Chul han, Byung. Topología de la violencia. Herder, Barcelona; 2016.

2 DEBORD, Guy. La sociedad de la apariencia. España, Pre-textos, segunda edición; 2015, p. 40.

${ }^{3}$ Instituto Nacional sobre el Abuso de Drogas; Institutos Nacionales de la Salud; Departamento de Salud y Servicios Humanos de los Estados Unidos de América. «El consumo de drogas y la salud» (11-11-2019). Disponible en:

https://easyread.drugabuse.gov/es/content/el-consumo-de-drogas-y-la-salud . https://doi.org/10.1590/s1020-49891998000100011 
${ }^{4}$ Corte revisará caso de uso lúdico de cocaína (11-11-2019). Disponible en: https:/ /www.excelsior.com.mx/nacional/corte-revisara-caso-de-uso-ludico-decocaina/ 1335416.

5 1a. CCLX/2016 $\left(10^{a}\right)$. Primera Sala. Décima Época. Gaceta del Semanario Judicial de la Federación. Libro 36, noviembre de 2016, pág. 897.

${ }^{6}$ Molina Germán. La legalización de las drogas en México. Milenio, 08-11-2013, (03-04-2019). Disponible en: http://www.milenio.com/opinion/german-molina/opinion/la-legalizacion-de-las-drogas-en-mexico

${ }^{7}$ Se presenta en México el Informe Mundial de Drogas 2019, 17 de julio de 2019, (11-11-2019). Disponible en: https://www.gob.mx/salud/prensa/227-se-presentaen-mexico-el-informe-mundial-de-drogas-2019. https://doi.org/10.18356/1730 c5b8- es

${ }^{8}$ El mapa de las adicciones en México (11-11-2019). Disponible en: https://saludy medicinas.com.mx/mamas/jovenes/estadisticas-del-consulmo-de-drogas-enmexico

${ }^{9}$ LORENA Ríos. Panorama de las adicciones en México, 05/12/2016 (11-11-2019). Disponible en: http://www.vertigopolitico.com/articulo/43443/Panorama-de-lasadicciones-en-Mexico. https://doi.org/10.20882/adicciones.663

$1070^{\text {a }}$ Asamblea Mundial de la Salud A70/29, 27 de marzo de 2017. La dimensión de salud pública del problema mundial de las drogas, p. 1 (11-11-2019). Disponible en: http://apps.who.int/gb/ebwha/pdf_files/WHA70/A70_29-sp.pdf. https:// doi.org/10.1590/s0864-34662008000100003

11 Oficina de las Naciones Unidas contra la Droga y el Delito; Informe Mundial sobre las Drogas 2017 (05-02-2019). Disponible en: https://idpc.net/es/publications/2017/06/informe-mundial-sobre-las-drogas-2017

12 Ídem.

${ }^{13}$ UNODC. El Informe Mundial sobre las Drogas 2019 hace un llamado a aumentar los recursos para ampliar la prevención y el tratamiento del consumo de drogas, julio 2019 (10-11-2019). Disponible en: https://www.unodc.org/mexicoandcentralamerica/es/webstories/2019/Informe_Mundial_Drogas_2019_Mexico.html https:// doi.org/10.18356/1730c5b8-es

${ }^{14}$ Corte Constitucional de Colombia, sentencia C-221/94, 5 de mayo 1994.

${ }^{15}$ Véanse, por ejemplo, Corte IDH, Caso de la Comunidad Mayagna (Sumo) Awas Tingni vs. Nicaragua (Fondo, Reparaciones y Costas), Sentencia del 31 de agosto de 2001, serie C, núm. 79, párrs. 146-148. Corte IDH, Caso Comunidad Indígena Yakye Axa vs. Paraguay (Fondo, Reparaciones y Costas), doc. cit., párr. 125; y Corte IDH, Caso de la Masacre de Mapiripán vs. Colombia (Fondo, Reparaciones y Costas), Sentencia del 15 de septiembre de 2005, serie C, núm. 134, párr. 106. https://doi.org/10.22201/iij.24487872e.2011.11.362

${ }^{16}$ Corte IDH, Caso 19 Comerciantes vs. Colombia (Fondo, Reparaciones y Costas), Sentencia del 5 de julio de 2004, serie C, núm. 109, párr. 173. 
Drogas y libre desarrollo de la personalidad, una nueva violencia

17 ARAIN, MARIAM, Y OTROS. Maturation of the adolescent brain, Saint James School of Medicine, Kralendijk, Bonaire. The Netherlands, press journal: Neuropsychiatric Disease and Treatment. 2013; 9: 449-461 (11-11-2019). Disponible en: https://doi.org/10.2147/NDT.S39776

${ }^{18}$ GIEDD. J. N. Structural magnetic resonance imaging of the adolescent brain. Annals of the New York Academy of Sciences. 2004; 1021: 77-85.

https://doi.org/10.1196/annals.1308.009

${ }^{19}$ Brook, J. S., Stimmel, M. A., ZhANG, C., \& BRook, D. W. (2008). The association between earlier marijuana use and subsequent academic achievement and health problems: a longitudinal study. The American journal on addictions. 17(2): 155-160 (11-11-2019). https://doi.org/10.1080/10550490701860930

${ }^{20}$ WAGNER, F.A. \& ANTHONY, J. C. From first drug use to drug dependence; developmental periods of risk for dependence upon cannabis, cocaine, and alcohol. Neuropsychopharmacology. 2002; 26: 479488 (11-11-2019). Disponible en: https:/ /doi.org/10.1016/s0893-133x(01)00367-0

${ }^{21}$ JACOBUS, J. Y TAPERT, S. Effects of cannabis on the adolescent brain. Curr Pharm Des. 2014; 20: 2186-2193 (11-11-2019).

DOI: $10.2174 / 13816128113199990426$

${ }^{22}$ ARISTÓTELES. Ética Nicomaquea, libro I, 1094a, 1-3.

${ }^{23}$ El gran argumento tradicional en favor de la libertad es la existencia de la responsabilidad moral, por la misma razón que «deber» implica «poder». Todo el mundo, deterministas e indeterministas, está de acuerdo en que sólo si el hombre es libre es también moralmente responsable de sus actos. https://doi.org/10.4272/ 978-84-9745-477-3.ch1

${ }^{24}$ Tribunal Constitucional de Alemania, BVerfGE 101, 361 (Carolina de Mónaco II), 15 de diciembre 1999.

25 Tribunal Constitucional de Alemania, BVerfGE 90, 145, 9 de marzo 1994.

${ }^{26}$ Herrera Fragoso, Agustín Antonio. La legalización de la Marihuana, posterior a la resolución de la SCJN, ETM y ANAYA, 2016.

${ }^{27}$ SPAemanN, Robert. Ensayos filosóficos. Madrid: Ediciones Cristiandad, trad. L. RODRÍGUEZ DUPLÁ. 2004, pp. 27-28. Citado por IRIZAR, LILIANA BEATRIZ, La naturaleza humana: ¿Obstáculo o garantía del libre desarrollo de la personalidad?» Díkaion, Año 25, Vol. 20, Núm. 2, pp. 279-297. Chía, Colombia, diciembre, 2011 (10-05-2019). Disponible en: http://www.redalyc.org/articulo.oa?id=72021402004. p.287. https://doi.org/10.5294/dika.2011.20.2.3

${ }^{28}$ BERLIN, ISAíAs. Dos conceptos de libertad. Madrid: Alianza, trad. A. Rivero; 2001, p. 54. Citado por IRIZAR, LILIANA BEATRIZ. La naturaleza humana..., p. 288.

${ }^{29}$ Suma Teológica, I, q. 82. Citado por IRIZAR, LILIANA BEATRIZ. La naturaleza humana...», p. 288.

30 StUART MILL, John, Sobre la libertad. Alianza, Madrid; 2009, cap. 1.

${ }^{31}$ StUART MILL, JoHN, El utilitarismo. Alianza, Madrid; 2007, cap. 2.

32 J. SANDEL, MichaEL. Justicia, ¿hacemos lo que debemos? El Liberalismo. Debate, España; 2011, p. 73.

Medicina y Ética - Abril-Junio 2020 - Vol. 31 - Núm. 2 


\section{A. A. Herrera Fragoso}

${ }^{33}$ Nozick, Robert. Anarquía, Estado y utopía. Fondo de Cultura Económica, México, 1988.

${ }^{34}$ STEIN, EDITH. La estructura de la persona humana. Madrid: BAC, trad. J. Mardomingo. 2003, p. 136. Citado por IRIZAR, LILIANA BEATRIZ, «La naturaleza humana...", p. 290.

${ }^{35}$ StEIN, EDITH. Op. cit., p. 137. Citado por IRIZAR, LIIIANA BEATRIZ, «La naturaleza humana...», p. 290.

${ }^{36}$ Cedpal Y KonRad Adenauer Stiftung. Declaración del Grupo Latinoamericano de Estudios sobre Derecho Penal Internacional con relación al problema de las drogas, octubre de 2015, p. 2 (10-05-2019). Disponible en: http://cedpal.unigoettingen.de/data/investigacion/GLEDPI/SeminariosGLEDPI/Declaracion Drogas.pdf https://doi.org/10.18356/e6c12c5e-es 